\title{
Penil plikasyon tekniği uygulanan konjenital penil kurvatür sonuçları
}

\section{Congenital penile curvature results using penile plication technique}

\author{
Fuat Kızılay', Mehmet Șahin¹, Barıș Altay
}

\section{öz}

AMAÇ: Penil plikasyon tekniği, konjenital penil kurvatür hastalığı tedavisinde kullanılan önemli bir tekniktir. Hastalarımızda bu tekniğinin başarısını ve sonuçlarını analiz etmeyi amaçladık.

GEREC VE YÖNTEM: Penil plikasyon tekniğiyle opere edilen 50 hastanın verileri retrospektif analiz edildi. Hastalara telefon yoluyla ulaşıldı ve kontrole çağrıldı. Hastaların işlemden genel memnuniyetleri, komplikasyon oranı, hastanede yatış süresi, kurvatür dereceleri, erektil fonksiyonları, ele gelen sertlik hissi sorgulandı.

BULGULAR: Olguların ortalama yaşı $29,75^{\prime}$ di (22-48). Ortalama kurvatür derecesi $40,1^{\circ}$ ydi. Hastalarda en sık ventral kurvatür saptandı. En sık saptanan kurvatür derecesi $45^{\circ}$ ydi (\%54). 40 hasta (\%80) postoperatif birinci gün eksterne edildi. On hastada (\%20) ele gelen lezyon hissi mevcuttu. Otuz altı hasta (\%72) işlemden genel olarak memnun olduğunu belirtti. Altı hastada minör komplikasyonlar görüldü, hiçbirisi girişim gerektirmedi. On hastada $(\% 20)$ rezidü $5^{\circ}$ kurvatür saptand, ancak hiçbirisi ikincil cerrahi gerektirmedi. Dört hasta, ele gelen lezyon hissi olduğunu (\%8) ve üç hasta, peniste hissizlik olduğunu (\%6) bildirdi. Kırk dört hasta, erektil fonksiyonlarında bozulma olmadığını (\%88) belirtti.

SONUÇ: Plikasyon tekniği, konjenital penil kurvatür tedavisinde yüksek hasta memnuniyeti ve düşük komplikasyon oranıyla uygulanan bir yöntemdir. Hastaların operasyondan beklentileri preoperatif dönemde iyi irdelenmeli ve hastaların imkansız beklentiler içerisinde olmaları önlenmelidir. Polyester sütürlerin kullanılmasıyla, ele gelen sertlik hissi azalmıştır.

Anahtar Kelimeler: erektil disfonksiyon, erkek ürolojik cerrahisi, penis hastalıkları

'Ege Üniversitesi Tıp Fakültesi, Üroloji Anabilim Dall, İzmir

\section{Yazıșma Adresi/ Correspondence:}

Uzm. Dr. Fuat Kızılay

Ege Üniversitesi Hastanesi Üroloji Anabilim Dalı, Bornova, izmir / Türkiye

Tel. $\quad+905325800685$

E-mail: fuatkizilay@gmail.com

Geliş/Received: $\quad$ 21.03.2017

Kabul/Accepted: $\quad 28.03 .2017$

\section{ABSTRACT}

OBJECTIVE: Penile plication technique is a fundamental technique used in the treatment of congenital penile curvature disease. We aimed to analyze the success rate and results of this technique in our patients. MATERIAL AND METHODS: We performed retrospective analysis of 50 patients who underwent penile plication. We reached the patients via telephone and called them for control. Patients' overall satisfaction associated with the procedure, complication rate, hospitalization time, the degree of curvature, erectile function and feeling of palpable lesion were questioned.

RESULTS: The mean age of the cases was 29.75 (22-48). The mean curvature degree was 40.1 . Ventral was the most common curvature direction. The most common curvature degree was $45^{\circ}$. Forty patients $(80 \%)$ were discharged on the first postoperative day. There was feeling of palpable lesion in 10 patients (20\%). Thirty-six patients (\% 72) declared that they were generally satisfied with the procedure. Minor complications were seen in 6 patients, none required intervention. Residual $5^{\circ}$ curvature was detected in 10 patients $(20 \%)$, but no secondary surgery was required. Four patients reported feeling of palpable lesion (8\%) and 3 patients had penile numbness (6\%). Fortyfour patients $(88 \%)$ reported no deterioration in erectile function.

CONCLUSION: Plication technique is a frequently performed method in the treatment of congenital penile curvature with a low complication rate and high patient satisfaction. Urologists must pay attention to patients' expectations from the surgery during the preoperative period and patients must be avoided from having impossible expectations. The use of polyester sutures has reduced the feeling of palpable lesion.

Keywords: erectile dysfunction, male urological surgery, penile diseases

\section{Giris}

Penil kurvatür (PK) sıklıkla konjenitaldir (primer), nadiren kazanılmış da (sekonder) olabilir. Konjenital PK, geç adölesan veya erken erişkinlik döneminde ortaya çıkabilir ${ }^{[1,2]}$ ve oldukça nadir görülür. Konjenital PK insidansının \%0,6 olduğu tahmin edilmektedir. ${ }^{[3]}$ Klinik anlamlı PK insidansı çok daha düşüktür ve PK ile birlikte görülen kurvatür ve seksüel disfonksiyonun derecesi de önemli oranda değişmektedir. ${ }^{[4]}$ Hipospadias ile birlikte görülme oranı artarken, \%4-10'a ulaşan prevalansı olduğunu bildiren ça- 
lışmalar da mevcuttur. ${ }^{[5]}$ Konjenital PK, sıklıkla korporal cisimlerin tunika albuginealarının orantısız büyümesinden kaynaklanır ve üretral malformasyonla ilişkili değildir. ${ }^{[6]}$ Vakaların çoğu ventraldir, ancak lateral ve nadiren dorsal de olabilir. ${ }^{[6]}$ Fallik gelişim, dördüncü gestasyonel haftada genital tüberkülün ortaya çıkmasıyla başlar. ${ }^{[7]}$ Distal üretra, frenulum ve çevresel prepusyumun komplet gelişimi üretral ve prepusyal kıvrımların ventral migrasyonuna bağlıdır. ${ }^{[8]}$ Tüm bunlar, bir orkestra harmoniğine benzer şekilde proksimal-distal yönde gerçekleşmektedir. ${ }^{[9]}$ Korpus kavernozumun gelişiminin üretral gelişime sekonder olduğu düşünülmektedir. ${ }^{[10]}$ İkinci ve üçüncü trimesterdeki parakrin testosteron üretiminin bu süreçteki rolü oldukça önemlidir. ${ }^{[11]}$ Yukarıdaki sinyal yolaklarındaki değişim, konjenital PK'ye neden olabilir. Kazanılmış PK, sıklıkla Peyronie hastalığı (PH) ile ilişkilidir. ${ }^{[12]}$ Ayrıca penil travma, genetik ve ailesel yatkınlık ve genital yoldaki geçirilmiş hastalıklar da kazanılmış PK nedenleri arasındadır. ${ }^{[12]}$

Penil kurvatürle başvuran bir vakada, kurvatürün derecesi, yönü ve hipospadias, üretral hipoplazi ve kriptoorşidizm gibi diğer genital anomaliler de sorgulanmalıdır. Tibbi ve cinsel öykü, tanı için çoğu zaman yeterlidir. Hastalar genellikle puberte sonrası ereksiyonların başlamasıyla başvurur ve kurvatürün derecesi arttıkça, cinsel birleşmeyi ciddi biçimde etkileyebilir. Self-fotoğraf veya vazoaktif ajanların kavernoz içi enjeksiyonu, kurvatür tanısının doğrulanması ve diğer patolojilerin dışlanması için faydalıdır. ${ }^{[13]}$

Tedavisi, puberte sonrası yapılan cerrahi onarımdır. Cerrahi yöntemlerin başarı oranları değişkendir. Örneğin, Essed-Schroeder tarafından tariflenen plikasyon tekniğinde nüks oranı \%10-20 arasında değişmektedir. ${ }^{[14,15]}$ On altı noktalı plikasyon tekniğiyle (16-nokta PT), ortalama 2,6 yıllık takip sonrası nüks oranı $\% 15^{\prime}$ dir. $^{[16]}$ Nükslerin ana nedeni, sütürlerde ereksiyon sonrası gevşeme veya kopma meydana gelmesi veya bağlanan sütür boyunca tunikada kesilme olmasıdır. Tunikal plikasyon temelli metodların diğer bir dezavantajı, kavernozal boşlukta kavernozal dokunun hacmini azaltan ve sıkıştıran tümsekli bir çıkıntının (tunika albugineanın tamamen kalınlaşması) oluşmasıdır. ${ }^{[17]}$ Aşırı katlanma da distal rijiditenin azalmasına yol açabilir. Plikasyon teknikleriyle opere olan hastaların yaklaşık üçte birinde, ele gelen dikişler veya çentiklerden kaynaklanan rahatsızlık hissi veya ağrı hissedilebilir. ${ }^{[16,18]}$ Diğer yandan, kavernoz boşluğun açılmasına gerek duyulmadan daha az girişimsel bir yöntem olması ${ }^{[1]}$, tunika albugineadan dorsal nörovasküler dal ayrılmadan (16-nokta PT tekniğiyle) yapılabilmesi ve kısa operasyon süresi bu tekniklerin başlıca avantajlarıdır. ${ }^{[16]}$
Nesbit ${ }^{[19]}$ veya Yachia ${ }^{[20]}$ tarafından tariflenen korporoplasti, daha iyi nüks oranları (\%5-15) sağlar (iyileşme sürecinde tunikal kenarların kalıı birleşmesiyle), ancak korporal boşluğun açılması nedeniyle daha girişimseldir, tunikal eksizyon veya insizyona bağlı erektil doku hasarlanabilir ve kanama meydana gelebilir. Bu nedenle, bu yöntemlerde sıklıkla bir turnike kullanılır. ${ }^{[18]}$ Penil dolaşım uzun süre kesilirse, erektil doku, erektil ve duyusal sinirler de zarar görebilir. Nesbit operasyonu sonrasında, sütüre edilen tunika albugineadan kaçağın neden olduğu postoperatif hematom da sık görülür. ${ }^{[21]}$

Tüm bu faktörleri göz önüne alarak, kliniğimizde konjenital penil kurvatür tedavisinde plikasyon tekniğini tercih ediyoruz. Bu çalışmada, plikasyon tekniğiyle opere ettiğimiz hastalarda retrospektif olarak, postoperatif hasta memnuniyeti, erektil fonksiyonu, kurvatür derecesini ve ele gelen sütür hissini, hastaları kontrole çağırarak değerlendirdik.

\section{GERECุ ve YÖNTEM}

Çalışmaya, 2010-2016 yılları arasında penil kurvatür tanısı alan ve penil plikasyon yöntemi ile tedavi edilen 62 hasta dahil edildi. Daha önce penil cerrahi geçiren, hipospadias, epispadias, mesane ekstrofisi tanısı alan 12 hasta çalışma dışı bırakıldı (Şekil 1). Geriye kalan 50 hastaya postoperatif değerlendirme için ulaşıldı. Tüm hastalar tam penil düzelme sağlanıncaya veya tekrar düzeltme operasyonu gerekmeyene kadar takip edildi. Hastaların ortalama takip süresi 42,58 aydı. Cerrahi tedavi uygulanan 50 hastanın karakteristik özellikleri kaydedildi.

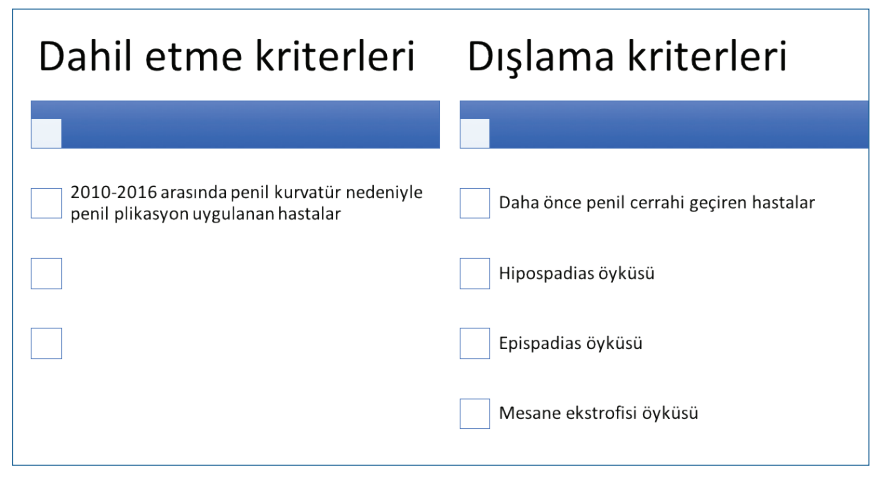

Şekil 1. Dahil etme ve dışlama kriterleri

\section{Cerrahi teknik}

Tüm hastalarda plikasyon tekniği kullanıldı. Anestezi indüksiyonun takiben intravenöz yoldan $1 \mathrm{gr}$ sefazol uygulandı ve üretral yoldan $16 \mathrm{fr}$ foley kateter tatbik edildi. Penis, korona seviyesinin altından çevresel olarak insize edilerek deglove edildi. Penis kökünden kauçuk penröz 


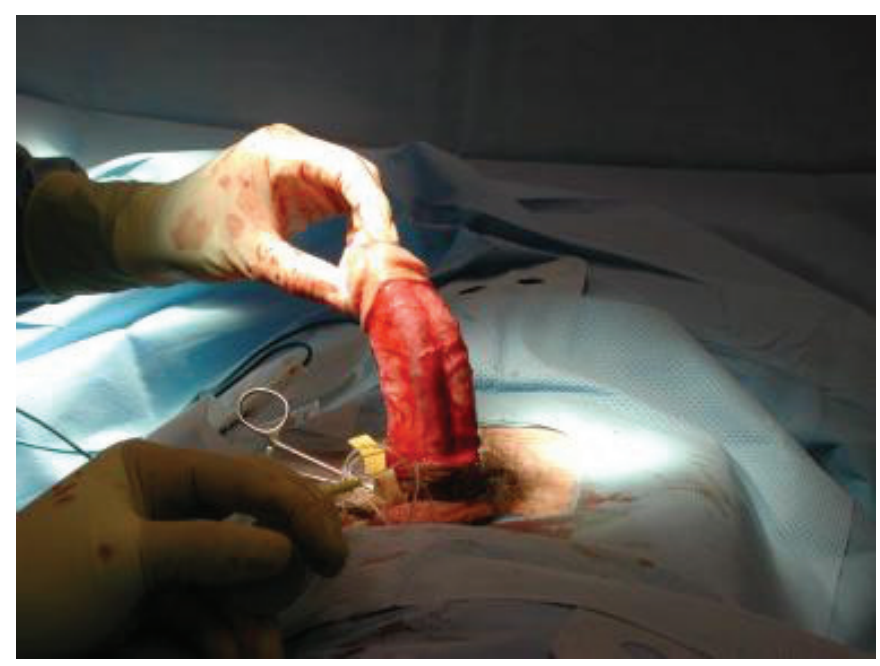

Şekil 1. Kelebek iğneyle yapay ereksiyon oluşturulması

dren bağlanarak, penil turnike uygulandı. Ardından, korpus kavernozum proksimal üçte birlik kısmından $21 \mathrm{G}$ plastik kelebek enjeksiyon iğnesiyle dik açıyla girilerek, serum fizyolojik ile yapay ereksiyon oluşturuldu (Şekil 1). Kurvatürün derecesi ve yönü teyit edildi. Ventral ve/ veya ventral-lateral kurvatürü olan vakalarda, nörovasküler demet diseke edildi. Ardından, kurvatürün aksi yönünde 2-0 Ethibond Excel polyester sütür ile plikasyon sütürleri geçilerek bağlandı. Tekrar yapay ereksiyon sağlanarak, kurvatürün giderildiği ve penisin düzgün hâl aldığı görüldü (Şekil 2). Düzelme olmazsa, ek sütürler ile düzelme sağlandı. Penis cildi 2-0 Vicryl Rapid’ sütür ile kapatıldı. Penise orta sıkılıkta distalden proksimale doğru rulo tampon ile bandaj uyguland.

Hastalara postoperatif dönemde telefonla ulaşıldı ve kontrole çağrılarak genel memnuniyetleri, komplikasyon oranı, hastanede yatış süresi, kurvatür dereceleri, erektil fonksiyonları, ele gelen sertlik hissi sorgulandı. Hastaların genel memnuniyetlerini sorgulamak için bir skala uygulanmadi. Bunun yerine, hastalara kontrollerinde yöneltilen "İşlemden genel olarak memnun kaldınız mı?” sorusuna hastaların "Evet" veya "Hayır" yanıtlarıyla değerlendirildi.

\section{BULGULAR}

Olguların ortalama yaşı 29,75'di (22-48). 50 hasta evliydi (\%80,64). Sirasiyla, ventral (50 hastanın 21'i, \%42), sol lateral (50 hastanın 10'u, \%20), sağ lateral (50 hastanın 8'i, \%16), dorsal (50 hastanın 8'i, \%16), sağ+ventral (50 hastanın 8'i, \%16), sol+sağ (50 hastanın 2'si, \%4) ve sol+ventral kurvatür (50 hastanın 2'si, \%4) saptandı (Tablo 1). Kurvatür derecesi $20-90^{\circ}$ (ortalama $40,1^{\circ}$ ) arasında değişmekteydi. 27 hastada kurvatür derecesi $45^{\circ}(27 / 50$ -\%54), 9'ar hastada $40^{\circ}$ ve $30^{\circ}(9 / 50-\% 18), 4$ hastada $35^{\circ}$

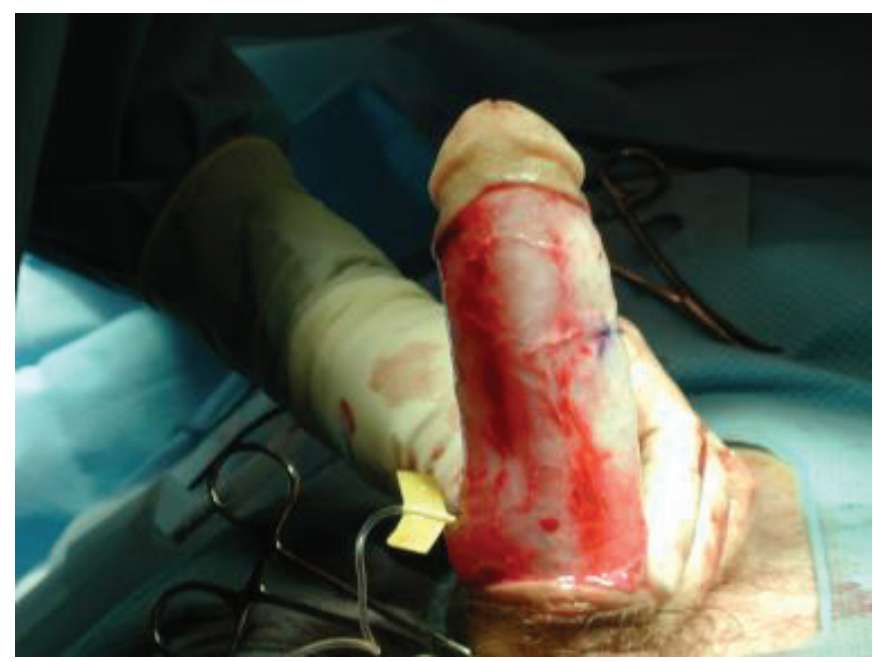

Şekil 2. İşlem sonrası penisin düzeldiğinin izlenmesi

(4/50-\%8) ve 1 hastada $20^{\circ}$ ydi (Tablo 2). Kurvatürü $20^{\circ}$ olan hastaya, ısrarcı kozmetik yakınmaları nedeniyle kurvatür onarımı yapıldı.

Kırk hasta postoperatif birinci gün taburcu edildi (40/50 -\%80), bir hastada gelişen postspinal baş ağrısı nedeniyle hospitalizasyon dört gün uzadı, dokuz hasta operasyon günü taburcu edildi.

On hastada, ele gelen lezyon hissi mevcuttu (10/50 -\%2). Otuz altı hasta işlemden genel olarak memnun olduğunu belirtti (36/50 -\%72).

Postoperatif değerlendirmeye tabi tutulan 50 hastanın altısında hafif komplikasyonlar görüldü: hematom $(n=2)$, ekimoz $(n=2)$, yüzeyel yara ayrılması $(n=1)$, postspinal baş ağrısı $(n=1)$. Yalnızca postspinal baş ağrısı gelişen hastanın yatışı dört gün uzadı. Diğer komplikasyonların hiçbirisi acil müdahale veya tekrar hastaneye yatış gerektirmedi. İlk kontrol zamanı 3 hafta -4 ay zaman aralığında, ortalama 1,5 aydı. Takipte 50 hastanın 36'sından (\%72) olumlu geribildirim alındı. Elli hastanın 10'unda birinci postoperatif vizitte bakiye penil kurvatür saptandı (\%20). Kırk hastanın postoperatif 1 . aydaki kontrollerinde kurvatür tamamen düzelirken (40/50 -\%80), altı hastada ventral $5^{\circ}$ deviasyon (6/50-\%12) ve dört hastada sol laterale $5^{\circ}$ deviasyon (4/50 -\%8) izlendi. Bakiye kurvatürü olan hastalarda ikincil operasyon gerekmedi.

Dört hasta ele gelen lezyon hissi olduğunu (\%8) ve üç hasta peniste hissizlik olduğunu (\%6) bildirdi. Kırk dört hasta erektil fonksiyonlarında bozulma olmadığını (\%88) belirtti. Penil kısalık belirten hasta olmadı.

\section{TARTIȘMA}

Konjenital penil kurvatür, ereksiyonların başlamasıyla ge- 
nellikle adölesan dönemde tanı alan ve cerrahi tedaviyle düzeltilebilen bir hastalıktır. Tunika albugineadan elipsoid bir dokunun çıkartılmasıyla karakterize bir teknik olan Nesbit, altın standart yöntem olarak kabul edilse de, plikasyon teknikleri daha düşük komplikasyon oranlarına sahip önemli alternatiflerdir. ${ }^{[22]}$ Nesbit yönteminin başlıca dezavantajları; penis boyunda kısalma, devam eden kurvatür ve doku eksizyonuna bağlı ereksiyonda bozulma meydana gelebilmesidir. ${ }^{[23]}$ Nesbit tekniği, konjenital kurvatürü tedavi etmek için 1965 'te tarif edilmiş ve $\mathrm{PH}$ 'yi tedavi etmek için ilk olarak 1975 'te kullanılmıştır.

1985 'te Essed ve Schroeder, konjenital ve kazanılmış PK'yi tedavi etmek için Nesbit tekniğinden esinlendikleri tekniklerini tarif ettiler. ${ }^{[24]}$ Penisi tamamen düzleştirmek için, maksimum kurvatür noktasına dört veya altı sütür atılan bu teknikle, birçok çalışmada uzun dönemde \%23-27 nüks oranları gösterilmiştir. Çalışmada ortalama takip süresi 39,8 aydı (12-75) ve preoperatif kurvatür açısı ortalama $47,4^{\circ}$ ydi $\left(20-90^{\circ}\right) .{ }^{[18]}$

1992'de Donatucci ve Lue, daha sonra Gholami ve Lue tarafından modifiye edilen basitleştirilmiş bir plikasyon tekniği tarif ettiler. Bu teknik, nörovasküler demetin alt seviyesinden tunika albugineaya uygulanan çoklu paralel plikasyon sütürlerinden oluşmaktadır. Serilerinde ortalama kurvatür açısı $30-120^{\circ}$ arasında değişmekle birlikte, ortalama $64^{\circ}$ ydi. $^{[16]}$

Ebbehoj-Metz tekniği, tunikadan dört pozisyondan atlamalı derin 2-0 Prolen sütürlerle penil tunika albugineanın plikasyonuyla yapılan bir tekniktir. Yirmi dört penil kurvatür hastası bu teknikle tedavi edilmiş, tamamında başarılı sonuç elde edilmiş, ancak ikisinde nüks kurvatür meydana gelmiştir. Vakaların kurvatür açıları $30-50^{\circ}$ arasında değişmekteydi. ${ }^{[25]}$ Bizim tekniğimiz de bu tekniğe benzemektedir.

Birçok çalışmada, yüksek oranda ele gelen lezyon hissi bildirilmiştir. Kırk altı PH bulunan vakanın dahil edildiği bir çalışmada, 26 hasta plikasyon tekniğiyle, 20 hasta ven grefti kullanılarak tedavi edilmiştir. Plikasyon tekniği, Gholami ve Lue'nun tarif ettiği 16-nokta PT tekniğiyle uygulanmıştır. Plikasyon grubunda \%81 (21/26), greft grubunda \%50 oranında (10/20) ele gelen lezyon hissi bildirilmiştir. ${ }^{[26]}$ Bazı hastaların ele gelen sütür hissi olsa da, cinsel birleşmeyi önlemediği sürece hasta tarafından önemli bir problem olarak görülmemektedir. Bizim çalışmamızda, ele gelen lezyon hissi $\% 8$ oranındaydı. Bunu, penisin üç katmanının (Buck ve dartos fasyası ve cilt) ayrı ayrı kapatılmasına ve böylece plikasyon sütürlerinin gömülerek hissedilirliğinin azalmasına bağlı olduğunu düşünüyoruz.
Mobley ve ark., PH tedavisinde plikasyon tekniklerini kullanmak için için penil kurvatür derecesinin 60'tan az olması gerektiğini bildirmiştir. ${ }^{[27]}$ Güncel bir derlemede, hafif-orta bakiye ventral PK'de $\left(<45^{\circ}\right)$ dorsal plikasyon tekniklerininin, ciddi bakiye ventral PK'de $\left(>45^{\circ}\right)$ ise ventral korporal uzatma tekniklerinin kullanılması gerektiği bildirilmiştir. ${ }^{[28]}$

Penil kurvatür onarımının başarısı, farklı tekniklerle \%85100 oranında bildirilmiştir. ${ }^{[29]}$ Hastalar komplikasyonların olabileceği konusunda bildirilmeli, penil kısalma, sütürlerden kaynaklanan peniste düzensizlik hissi, penil ödem ve cerrahi sonrası 2-6 hafta boyunca ereksiyonda ağrı olabileceği konusunda bilgi verilmelidir. Bir çalışmada, 27 hastaya penil plikasyon uygulanmış ve ortalama $4(2-10)$ sütür kullanılmıştır. Üç hastada, plikasyon sahasında sütür granülomları ve düzensizlik bildirilmiştir. ${ }^{[30]}$ Glansta geçici hissizlik bilinen bir komplikasyondur, ancak 139 vakanın opere edildiği bir çalışmada, Nesbit tekniğiyle opere edilen bir vakada kalıcı olduğu bildirilmiştir. ${ }^{[31]}$ Yazarlar, penil rekonstrüktif cerrahinin tecrübeli ellerde yapılması gerektiğinin alını çizmiştir. Çalışmamızda, üç hastada (\%6) peniste hissizlik saptadık.

Postoperatif ED önemli bir risk gibi gözükmemektedir. Plikasyon cerrahisi sonrası uzun dönem cinsel fonksiyonların sorgulama formlarıyla araştırıldığı bir çalışmaya 58 hasta dahil edilmiştir. Hastaların \%95'i ereksiyonlarının korunduğunu bildirmiştir. ${ }^{[4]}$ Muhtemelen uzamış turnike süresine bağlı yalnızca bir vakada penil nekroz bildirilmiştir. Baskin ve ark., tunika albugineanın kalınlığı ve gücüyle ilişkili detaylı penil innervasyon çalışmalarını bildirmişler ${ }^{[32]}$; saat 11 ve 1 hizasında hiç dorsal sinir olmadığını, ancak tunika etrafinda yoğun biçimde bulunduğunu göstermişler; penisin dorsal yüzeyinde saat 12 hizasında hiç sinir veya damar olmadığını ve plikasyon sütürü yerleştirmek için tunika albugineanın diseksiyonunun gerektiğini belirtmişlerdir. Çalışmamızda, hastalarımızın $\% 88^{\prime} \mathrm{i}$, postoperatif dönemde erektil fonksiyonlarında kötüleşme olmadığını ifade etmiştir.

Bacal ve ark.'nın çalışmasında, hastaların tahmin ettikleri kurvatür açıları ile objektif ölçümleri karşılaştırılmıştır. ${ }^{[33]}$ Seksenbir hastanın dahil edildiği çalışmada, hastaların kurvatür açılarını gerçekte olduğundan ortalama $20^{\circ}$ daha fazla tahmin ettiklerini saptamışlardır. Hastalar sıklıkla $15^{\circ}$ 'nin üzerinde rezidü kurvatür için ikincil cerrahiyi tercih etmektedir. Bizim çalısmamızda, 10 hastada (\%20) $5^{\circ}$ bakiye kurvatür saptandı ve bu hastalar ikincil operasyonu istemedi. Bu konuda preoperatif dönemde hastaları bilgilendirmek ve ilişkiye engel olmayacak düzeyde bakiye kurvatür olabileceğini söylemek gerekmektedir. 
Penil plikasyon, plak insizyonu ve greftlemeye göre daha kısa operasyon süresine sahiptir ve plikasyon uygulanan erkekler greft uygulananlara göre daha rijid bir penise ve daha az ele gelen sütür hissine sahiptir; cinsel ilişki kurma yetenekleri daha yüksek ve cinsel ilişkide daha fazla his duymaktadırlar. ${ }^{[34]}$ Greenfield ve ark., penil plikasyon tedavisi uygulanan 102 penil kurvatür hastasının retrospektif analizini yapmışlardır. ${ }^{[35]}$ Hastalara takip için telefon ile ulaşılmış, anket formu doldurulmuştur. Ortalama izlem süresi 29 ay olup, hastaların \%99'u cerrahiden sonra penislerinin düz olduğunu bildirmiştir. Ortalama penis uzunluğu kaybı $0,36 \pm 0,5$ cm'dir $(0-2,5$ $\mathrm{cm})$. Yazarlar, ameliyat sonrası penis uzunluğunun kaybıyla ilgili üç faktör tanımlamıştır: Preoperatif penis uzunluğu, geniş açlı kurvatür ve ventral yerleşimli kurvatür.

\section{SONUC}

Konjenital penil kurvatür cerrahi tedavisinde penil plikasyon tekniği, yüksek oranda hasta memnuniyetiyle başarryla uygulanabilen bir yöntemdir. Kurvatür, en sık ventral yönde izlenmekte ve nörovasküler demet ve üretranın hasarlanmaması için özen gösterilerek, plikasyon tekniği çok düşük komplikasyon oranları ile uygulanabilmektedir. Hastaların preoperatif erektil fonksiyonları iyi değerlendirilmeli ve tedaviden beklentileri hastalarla ayrıntılı şekilde konuşulmalıdır. Ethibond Excel polyester sütür kullanılmasıyla, geçmişte sıklıkla karşılaşılan ele gelen sertlik ve irritasyon hissi son dönemde oldukça azalmıştır.

\section{KAYNAKLAR}

1. Makovey I, Higuchi TT, Montague DK, Angermeier KW, Wood HM. Congenital penile curvature: update and management. Curr Urol Rep 2012;13:290-7. PubMed PMID:22688922. doi: 10.1007/s11934-012-0257-x

2. Hsieh JT, Liu SP, Chen Y, Chang HC, Yu HJ, Chen CH. Correction of congenital penile curvature using modified tunical plication with absorbable sutures: the long-term outcome and patient satisfaction. Eur Urol 2007;52:261-6. doi: 10.1016/j. eururo.2006.12.033

3. Yachia D, Beyar M, Aridogan IA, Dascalu S. The incidence of congenital penile curvature. J Urol 1993;150(5 Pt 1):1478-9. PubMed PMID:8411431.

4. Baldini A, Morel-Journel N, Paparel P, Ruffion A, Terrier JE. Patient-reported long-term sexual outcomes following plication surgery for penile curvature: A retrospective 58-patient study. Prog Urol 2017;27:10-6. doi: 10.1016/j.purol.2016.08.018

5. Montag S, Palmer LS. Abnormalities of penile curvature: chordee and penile torsion. ScientificWorldJournal 2011 Jul 28;11:14708. PubMed PMID:21805016. doi: 10.1100/tsw.2011.136

6. Hatzimouratidis K, Giuliano F, Moncada I, Muneer A, Salonia A, Verze P . EAU Guidelines on Erectile Dysfunction, Premature Ejaculation, Penile Curvature and Priapism; 2016.

7. Cunha GR, Baskin L. Development of the penile urethra. Adv Exp Med Biol 2004;545:87-102. PubMed PMID:15086022.
8. Hynes PJ, Fraher JP. The development of the male genitourinary system: III. The formation of the spongiose and glandar urethra. Br J Plast Surg 2004;57:203-14. PubMed PMID:15006521. doi: 10.1016/j.bjps.2003.08.017

9. Perriton CL, Powles N, Chiang C, Maconochie MK, Cohn MJ. Sonic hedgehog signaling from the urethral epithelium controls external genital development. Dev Biol 2002;247:26-46. PubMed PMID:12074550. doi: 10.1006/dbio.2002.0668

10. Baskin LS, Lee YT, Cunha GR. Neuroanatomical ontogeny of the human fetal penis. Br J Urol 1997;79:628-40. PubMed PMID:9126098.

11. Cohn MJ. Development of the external genitalia: conserved and divergent mechanisms of appendage patterning. Dev Dyn 2011;240:1108-15. PubMed PMID:21465625. Pubmed Central PMCID. PMC4761266. doi: 10.1002/dvdy.22631

12. Sasso F, Vittori M, D’Addessi A, Bassi PF. Penile curvature: an update for management from 20 years experience in a high volume centre. Urologia 2016;83(3):130-8. PubMed PMID:27103093. doi: $10.5301 /$ uro. 5000169

13. Maretti C. Symptoms, Their Physiopathology, and Outpatient Clinical Practice and Diagnosis. Peyronie's Disease: Springer; 2015. p.47-57.

14. Friedrich MG, Evans D, Noldus J, Huland H. The correction of penile curvature with the Essed-Schroder technique: a long-term follow-up assessing functional aspects and quality of life. BJU Int 2000;86:1034-8. PubMed PMID:11119097.

15. Leonardo C, De Nunzio C, Michetti P, Tartaglia N, Tubaro A, De Dominicis C, et al. Plication corporoplasty versus Nesbit operation for the correction of congenital penile curvature. A long-term follow-up. Int Urol Nephrol 2012;44:55-60. PubMed PMID:21559790. doi: 10.1007/s11255-011-9976-z

16. Gholami SS, Lue TF. Correction of penile curvature using the 16-dot plication technique: a review of 132 patients. J Urol 2002;167:2066-9.

17. Ryu J-K, Suh J-K. Penile Reconstruction in Peyronie's Disease. Penile Augmentation: Springer; 2016. p.213-23.

18. Schultheiss D, Meschi MR, Hagemann J, Truss MC, Stief CG, Jonas U. Congenital and acquired penile deviation treated with the essed plication method. Eur Urol 2000;38:167-71. PubMed PMID:10895008. doi: 20275

19. Akbulut F, Akman T, Salabas E, Dinçer M, Ortac M, Kadioglu A. Neurovascular bundle dissection for Nesbit procedure in congenital penile curvature patients: medial or lateral? Asian J Androl 2014;16:442-5. doi: 10.4103/1008-682X.123667.

20. Lopes I, Tomada N, Vendeira P. Penile corporoplasty with Yachia's technique for Peyronie's disease: Single center experience with 117 patients. Urol Ann 2013;5:167-71. doi: 10.4103/09747796.115736

21. Chen R, McCraw C, Lewis R. Plication procedures -excisional and incisional corporoplasty and imbrication for Peyronie's disease. Transl Androl Urol 2016;5:318-33. doi: 10.21037/tau.2016.05.01

22. Shaeer O. Shaeer's corporal rotation for length-preserving correction of penile curvature: modifications and 3-year experience. J Sex Med 2008;5:2716-24. PubMed PMID:18624969. doi: 10.1111/j.1743-6109.2008.00913.x

23. Andrews HO, Al-Akraa M, Pryor JP, Ralph DJ. The Nesbit operation for Peyronie's disease: an analysis of the failures. BJU Int 2001;87:658-60. PubMed PMID:11350407.

24. Essed E, Schroeder FH. New surgical treatment for Peyronie disease. Urology 1985;25:582-7. PubMed PMID:4012950. 
25. Raimoldi A, Berti GL, Giola V, Longoni E, Paccaduscio A, Pozzoni F, et al. Our experience in the treatment of penile curvature. Arch Ital Urol Androl 2004;76:66-8.

26. Kim DH, Lesser TF, Aboseif SR. Subjective patient-reported experiences after surgery for Peyronie's disease: corporeal plication versus plaque incision with vein graft. Urology 2008;71:698-702. PubMed PMID:18387398. doi: 10.1016/j.urology.2007.11.065

27. Mobley EM, Fuchs ME, Myers JB, Brant WO. Update on plication procedures for Peyronie's disease and other penile deformities. Ther Adv Urol 2012;4:335-46. PubMed PMID:23205060. Pubmed Central PMCID. PMC3491756. doi: $10.1177 / 1756287212448224$

28. Schlomer BJ. Correction of Residual Ventral Penile Curvature After Division of the Urethral Plate in the First Stage of a 2-Stage Proximal Hypospadias Repair. Curr Urol Rep 2017;18:13. PubMed PMID:28213855. doi: 10.1007/s11934-017-0659-x

29. Vicini P, Di Nicola S, Antonini G, De Berardinis E, Gentile V, De Marco F. Geometrical modified nesbit corporoplasty to correct different types of penile curvature: description of the surgical procedure based on geometrical principles and long-term results. Int J Impot Res 2016;28:209-15. PubMed PMID:27511302. doi: 10.1038/ijir.2016.28
30. Erpenbach K. Penile plication for the treatment of severe penile deviations. Dtsch Med Wochenschr 1990;115:1746-9. doi: $10.1055 / \mathrm{s}-2008-1065220$

31. Yachia D. Our experience with penile deformations: incidence, operative techniques, and results. J Androl 1994;15:63S-8S.

32. Baskin LS, Erol A, Li YW, Liu WH. Anatomy of the neurovascular bundle: is safe mobilization possible? J Urol 2000;164:977-80.

33. Bacal V, Rumohr J, Sturm R, Lipshultz LI, Schumacher M, Grober ED. Correlation of degree of penile curvature between patient estimates and objective measures among men with Peyronie's disease. J Sex Med 2009;6:862-5. PubMed PMID:19284472. doi: 10.1111/j.1743-6109.2008.01158.x

34. Kim DH, Lesser TF, Aboseif SR. Subjective patient-reported experiences after surgery for Peyronie's disease: corporeal plication versus plaque incision with vein graft. Urology 2008;71:698-702. doi: 10.1016/j.urology.2007.11.065

35. Greenfield JM, Lucas S, Levine LA. Factors affecting the loss of length associated with tunica albuginea plication for correction of penile curvature. J Urol 2006;175:238-41. doi: 10.1016/S00225347(05)00063-7 